\title{
CHAPTER NINETEEN
}

\section{SOCIAL MEDIA AS INFORMATION DISSEMINATION TOOLS DURING COVID 19 PANDEMIC ERA}

\author{
Lateef, Elizabeth Bukunola \\ Principal Librarian, Crawford University \\ Library, Faith City, Igbesa, Ogun State, Nigeria. \\ Adesanmi Mathew Farukuoye \\ Senior Librarian, College Library, \\ College of Health Sciences and Technology, \\ Ijero Ekiti, Ekiti State, Nigeria. \\ Olomola, Abosede, Racheal Funmilola \\ Student Records, Registry Unit \\ University of Ibadan, Nigeria
}

\begin{abstract}
This paper conceptualizes the role that Social Media platforms are playing in the dissemination of information during the COVID 19 pandemic era. It captures the positive and negative impact of COVID 19 outbreak; how information is disseminated during COVID 19 pandemic; the place, categories, and importance of Social Media in the dissemination of information during COVID 19 pandemic. The paper concluded that Social Media has become predominant in the public dissemination of indispensable information about the pandemic. It remains an important avenue for health practitioners, government, industries, public health organizations, school administrators and individuals. It was suggested that precise information should be propagated by experts and authorities to avoid the inability to get reliable information when the need arises. Responsible citizens were also advised to desist from spreading erroneous information and learn to substantiate and confirm information before spreading it.
\end{abstract}

Keywords: Social Media, COVID 19, pandemic, information dissemination.

\section{Introduction}

The Coronavirus disease, popularly known as COVID 19 is a pneumonia of unknown cause that originated in Wuhan, China in December, 2019 and consequently spread worldwide through the movement of people. It is the fifth recorded pandemic, the first being the flu pandemic that broke out in 1918. The pandemic crises have affected many countries and the number of infected cases keep rising. COVID 19 is highly contagious and can be spread from person to person through respiratory droplet that is produced by an infected person through 


\section{COVID-19: THE CHANGING LANDSCAPE OF HIGHER EDUCATION IN NIGERIA}

sneezing, coughing or while talking. The symptoms of COVID 19 is similar to that of common cold and majority of those infected with this virus will experience mild to moderate fever and respiratory illness. It can be so severe to the extent that a ventilator will be needed to aid breathing. Other notable symptoms are dry cough, sore throat, nasal congestion, body weakness and headache. Presently, there is no vaccine for this virus. The only preventive measure is to practice good hygiene like washing of hands with soap and water or alcoholbased hand sanitizer; keeping nose and mouth covered with a mask, maintaining social distance and coughing into bent elbow. Also, suspected infected people are advised to self-isolate.

\section{Impact of COVID-19 Outbreak}

The COVID 19 outbreak has devastated virtually all sectors and left scars in the social, economic, political, cultural and educational, religion sectors. People are losing jobs. Businesses are crumbling. Schools and worship centres are closed. Ceremonies and social events are on hold and there is no way of knowing when normalcy will return. The Nigerian economy is not left out in the negative effect of the pandemic perhaps as a result of decline in consumption, investment, net export and increased government expenditure. Restriction of movement in the form of social distancing, lockdown and border closure are the reasons for this decline. For example, restriction of movement has constrained consumers to spend only on goods and services that are essential. The crises have also resulted in drastic collapse of stock prices with the Nigerian Stock Exchange recording its worst performance since the 2008 financial crises, leading to the erosion of investors wealth (Onyekwena \& Ekeruche, 2020).

From all indication, the health sector is the most hit by the COVID19 pandemic, especially in Africa where most of the health facilities have deteriorated. Despite all measures adopted to minimize the spread of the disease, the number of cases keep rising significantly. Isolation centres and public hospitals are filled up and overwhelmed while private hospitals are afraid to admit infected patients, leading to the death of many (Ozili,2020). Furthermore, the pandemic has affected religion in different ways. Services of different faith were cancelled, including pilgrimages to holy lands. The yearly Easter celebration services for Christians could not hold in year 2020, courtesy of the pandemic. The element of worship participation has significantly been affected as most religion have quickly adopted to the situation by livestreaming their services, using the media such as television, radio and social media.

The spheres of education and learning is also seriously affected by the COVID 19 pandemic leading to closure of schools. School closure is an important backbone of social distancing tool that is used to curb the spread of the pandemic. Some school facilities were even used as makeshift hospitals and isolation centres. This, inadvertently will cause lengthier disruption of education services, making the buildings unavailable for education purpose. This made schools all over the world (including Nigeria) to adapt to online modalities for teaching during the pandemic era (UNESCO, 2020). 


\section{COVID-19: THE CHANGING LANDSCAPE OF HIGHER EDUCATION IN NIGERIA}

Due to the pandemic, most private schools and universities had to resort to online/remote form of learning so that students can continue to learn. The government also made provision for public school students using the mass media, specifically the radio and television. However, the problem with this online/remote teaching is that the vulnerable children were not considered since most of them may not have access to Social Media or even television and radio. Not only that, it is only children whose parents have smart phones that can have access to online teaching and some children are not living with their parents, perhaps with their grandparents who may not even know how to use smart phone not to talk of owning one. Another key issue is that most parents may not be able to devout their time to remote learning neither do they possess the cognitive skills to access the best online materials. The difficulty of helping children learn what their parents do not understand is a big issue. Therefore, from all indication, the COVID 19 interruption has affected learning because there is no way school children and University students will not miss out too much all through. It is therefore obvious that even though home/online schooling will produce some inspirational moments, some fun moments and even some frustrating moments, there is no way it can replace the learning lost from school (Burgess and Sievertsen, 2020). Having said much about the negative impact of COVID 19 pandemic, there seems to be some noticeable positive impact from the ongoing pandemic:

1. Enhanced Hygiene: Naturally, constant washing of hands is not a regular hygiene practice that most people are used to. However, the pandemic has necessitated this practice as part of the safety measure to contain the spread of this deadly virus. Consequently, this habit will most likely remain as part of people's health etiquette even after the pandemic is over, thereby ensuring that their well-being is well maintained.

2. A Cleaner World: The lockdown down that took place in almost all the countries affected by the pandemic have resulted into a significant drop in greenhouse gas emission., definitely because factories were closed, transportation brought to a standstill and social movement restricted. Carbon footprint has drastically reduced, bringing about an improvement in air quality due to the reduction in the burning of fossil fuels.

3. A Stimulant for Digital Metamorphosis: The COVID 19 pandemic also necessitated a digital transformation in all sectors. The disruption in the normal way of living brought about a 'new normal'. Since businesses and transactions need to thrive, school children and students need to continue learning and people must progress in life despite the lockdown, there was no choice than to adopt digital tools and platforms for communication and transaction. The truth is that this 'new normal' may remain as our normal means of communication, transaction and interaction even after the pandemic (Ajifowoke, 2020). 


\section{COVID-19: THE CHANGING LANDSCAPE OF HIGHER EDUCATION IN NIGERIA}

\section{Information Dissemination During COVID-19}

Information is a vital element in disease prevention; hence the media must be ready to take up the responsibility of keeping the populace properly informed in an understandable, clear yet forceful manner. The populace not being properly informed about preventive and protective measures during and emergence of an epidemic or pandemic as the case may be can have serious repercussions (Mejia, et al, 2020). Access to quality information during a pandemic like COVID 19 is germane. It is the foundation for knowledge. Access to information gives room to freedom of expression, making it meaningful and helpful to the society. Confirmable and authentic information like those published in scientific and professional journals is the pointer to building a 'knowledge society'. The internet is presently the major dissemination tool for information. It reinforces the transmission process, enabling the flow of messages. The internet helps guarantee high speed digital connectivity, helping people cope with the pandemic by allowing them to learn, work and socialise with friends from home during the shutdown. Also, through the internet, government is able to give direct public health information to the populace. Journalists are also able to reach larger audience about the pandemic (Possetti \& Bonticheva, 2020).

With the aid of Information Communication Technology (ICT), awareness about infectious disease is much easier in this dispensation. People are informed about the disease through different avenues like Television news, mouth to mouth communication, print media, radio and house to house sensitization. The level of awareness of an individual about the outbreak will determine how he/she reacts to the disease transmission. Those who are aware about the disease outbreak will easily take preventive measures so as not to be infected (Zhao et al, 2020). Collinson, Khan \& Hefferson (2015) also corroborated this point by asserting that the media's report on an epidemic or pandemic outbreak can help inform the public and in turn induce positive healthy behaviour practices like hand washing, social distancing, coughing into bent elbow, etc. This will go a long way in reducing the probability of contacting the disease.

\section{Meaning of Social Media and Its Importance in the Dissemination of Information}

Social Media is an internet-based technology, website and applications that facilitates content creation and sharing, and that also allow people to participate in social networking through the building of virtual networks and communities. Contents in Social Media includes personal information, documents, videos and photos. People can engage in Social Media via computer, smartphones and tablets. Initially, Social Media was basically used to interact with friends and families but it is now adopted by businesses for online marketing of their products. It is a platform used by companies to engage with customers, promote, gauge customer trends and also offer customer services.

People are using various types of Social Media platforms to connect with people online for different kind of reasons. Most of these platforms possess rich capacity features like video and 


\section{COVID-19: THE CHANGING LANDSCAPE OF HIGHER EDUCATION IN NIGERIA}

live streaming, content sharing, online content publishing, etc. According to Foreman (2017), Social Media are in different categories. Below are the categories and their uses:

1. Social Networks - examples of such are facebook, Linkedin, and Twitter. Social Media are used to connect with people. They help people connect online to share information and ideas. These Social Media networks have metamophorsized to become hubs that have practically changed nearly every aspect of modern life. It allows people to connect with family and friends.

2. Media Sharing Networks: good example s of this kind of Social Media networks are Instagram, snapshat, vimeo, youtube, etc and they are used to find and share video, live video, photos and other media online. However, it is good to note that presently, there is a very thin line between media sharing networks and social networks because networks like facebook abd twitter have added live streaming, live video and other multimedia services to their functions.

3. Discussion Forums - example of such are zoom, Digg, Quora, reddit, etc. The purpose of this kind of network is to find, discuss and share information.

4. Social Blogging Networks - this kind of Social Media network permits content publishing and it is a great way of building engagement with one's audience.

The big advantage of Social Media is that it can be used to connect and share information with anyone and anywhere on earth and with many people simultaneously. It is also worthy to note that Social Media is an ever changing and ever evolving web based platform. People use the Social Media for different reasons. Some to keep in touch with friends and families; some to network career opportunities and to find people across with like interest (Dollarhide, 2019).

\section{The Social Media and Information Dissemination During COVID-19 Pandemic}

Social Media has made enormous progress in this dispensation in term of their functionality and communication. It is a source of verifiable information. For instance, the government, World Health Organization (WHO) and other public health organizations like the NCDC (Nigeria Centre for Disease Control) in Nigeria took advantage of the Social Media to sensitize the public about the outbreak and control panic. Also, Social Media was a means of communication with the outside world for those suspected to have contacted the disease and were quarantined in their homes or hospitals. With the aid of the Social Media, infected people were able and eager to tell their stories and documented their challenges in the face of the deadly disease. Social Media was the only avenue for people to stay in touch with friends, families and the world at large doing the lockdown that was necessitated by the outbreak. Also, people were able to get the latest news, updates and even order for food via the Social Media. Furthermore, Social Media was instrumental in ameliorating the situation. Through Social Media, people raised funds for government and also gave palliative to the vulnerable in the society. Researchers also used Social Media platforms to collaborate and distribute their questionnaires to their respondents. The Social Media served as a grieving space. It provided 


\section{COVID-19: THE CHANGING LANDSCAPE OF HIGHER EDUCATION IN NIGERIA}

a platform for people to support and encourage one another on the disease raged (Sokolov, 2020).

During the outbreak of the Severe Acute Respiratory Syndrome (SARS) that affected China, Hongkong and Canada in 2000 before the advent of Social Media, text and instant messaging was a major means of communication. Presently, the Social Media, with over 2.9 billion users worldwide has transformed the world of communication compared to the traditional means of communication like the television and print media. It gives room for immediate dissemination of information which is much needed in alerting the public and health practitioners about evolving treatment and guidelines (Tsui, et al, 2020).

The use of Social Media can be complex. It can be a source of information, connection, entertainment or a reflection of what is on one's mind. Globally, the pandemic is presently what is on everybody's mind. Social Media can be of great help for people who are feeling anxious and isolated as a result of the pandemic. It can serve as a source of connection with others through video chats and conferencing or messenger applications. Using the Social Media as a platform for sharing useful information with friends and family can help deal with fear and anxiety during this COVID 19 pandemic era (Wiederland, 2020). Depoux, et al (2020) opined that the Social Media can be exploited to supplement the needed sensitization of the public on the need to follow laid down quarantine procedure. This will help eradicate the spread of fear and uncertainty.

Social Media has increased the creation of research networks and collaborations. The twitter, a Social Media platform in particular have been widely used by health practitioners to make short posts with up to 280 characters with an image or link to another website. It is being used to post regular update for the general public during the COVID 19 pandemic. Twitter is also used to alert twitter followers about recently published peer-reviewed articles online. Twitter users can also help accentuate a post by retweeting another user's post by commenting on it (Tsui, et al, 2020).

\section{Limitation of the Social Media in the Dissemination of Information During Covid-19 Pandemic.}

It is expedient to note that the Social Media contributed to the spread of misinformation about the outbreak. It was used as an instrument in propagating misleading rumours and conspiracy theories about the virus, coupled with the fear mongering, racism and panic purchase of essentials like facemask, hand sanitizers and the rest. The truth is that the panic occasioned by Social Media travelled faster than COVID-19 spread, thereby hampering the response. This panic needs to be combated. Creating an interactive platform to counter rumours about the coronavirus pandemic would enable the government, public health organizations and stakeholders to respond with an engaging and proactive information that can change the narrative of misinformation (Depoux,et al, 2020). Misinformation, termed 'infodemic' by World Health Organization (WHO) has been discovered to be the major problem to COVID 


\section{COVID-19: THE CHANGING LANDSCAPE OF HIGHER EDUCATION IN NIGERIA}

19 control. Infodemic refers to the unrestricted magnitude of information which are mostly false about the COVID 19 outbreak, making it difficult to access essential information. Infodemic can spring up from different sources - from a leader to the led, from short video clips on Social Media platforms like twitter handles, facebook, Instagram, etc. Infodemic affects health seeking behaviour negatively. It lowers the perceived severity and susceptibility of the disease, thereby increasing the risk of contracting the disease. This calls for simple and easy to understand information sharing system, especially among the illiterate community. Making information available with the use of local languages and pictorial forms that people could easily relate and understand will enable wider coverage and better understanding of the disease (Olajuwon, 2020). Misinformation can be categorized into different levels-bad science, that is medical practitioners that deliberately fuel exaggerated or unsubstantiated fears. The other category includes those that sees the outbreak as an opportunity to make financial gains and those that sees it as a political opportunity to polarize the society. There are also the 'super spreaders' who circulate misinformation through Social Media. Lastly, we have the misunderstood or inadequate information that might be circulating generally. Larson (2018) strongly advocates that the torrent of opposing information, misinformation and manipulated information on Social Media should be seen as a global and public health threat. Notwithstanding, this threat can be curbed by detecting early signals of rumours and address them before they escalate. In addition, news and Social Media should be monitored and people's attitudes surveyed and tracked.

Tsui, et al (2020) advocated the need to put in mind the potential pitfalls of the Social Media. As a result of the "over-abundance" of information during the COVID 19 pandemic, it may be difficult to find reliable information. Although Social Media has the ability to disseminate information fast and globally, the content most times is not moderated. Oh, Lee, and Han (2020) also asserted that information acquisition and exchange through Social Media during an outbreak can worsen communication about the disease since emotion plays a substantial role in shaping public risk perception. Emotions like fear and anger arbitrates between Social Media exposure, personal- level risk perception and preventive behaviour. In other words, exposure to Social Media during an outbreak can evoke extreme self-relevant emotions and subsequently increase personal-level risk perception and preventive behaviours.

\section{Conclusion}

Social Media is playing a remarkable role in the dissemination of information during the COVID 19 pandemic era. It has become predominant in the public dissemination and discussion of indispensable information about the pandemic. Social Media has the ability to spread information at fast rate and at the same time gives room for exaggeration and rumour. Notwithstanding the negative aspect of Social Media, COVID 19 pandemic has succeeded in revealing the positive role of Social Media and how it has become pivotal to public dissemination of information and discussion about the pandemic. As the COVID 19 pandemic continue to evolve, the Social Media still remains an important avenue for health practitioners, government and public health organization, industries, school administrators and individuals 


\section{COVID-19: THE CHANGING LANDSCAPE OF HIGHER EDUCATION IN NIGERIA}

to get in touch with the populace and also update their knowledge about this dreaded infectious disease

\section{Suggestions}

Based on the discuss in this paper, below are my suggestions:

1. Precise information should be propagated by experts and authorities to avoid the inability to get reliable information when the need arises.

2. Social Media should put their business perspective aside and be more concerned about global welfare. They should work towards ensuring that truthful information from reliable sources are disseminated to create the needed awareness.

3. Responsible citizens should refrain from disseminating erroneous information and learn to substantiate and confirm information before spreading it.

4. The potential pitfalls of the Social Media should be noted as a result of the overabundance of information doing the COVID 19 pandemic.

5. Misinformation on Social Media should be seen as a global threat and defaulters should be dealt with appropriately.

\section{Reference}

Ajifowoke, M.G. (2020). Here are four positive effects of the COVID 19 Pandemic.

Available at http://venturesafrica.com/covid-19-here-are-some-positive-lights-amidthe-devastating-pandemic/. Accessed on June 12, 2020.

Burgess, S., Sievertsen, H.H. (2020). Schools, skills, and learning: The impact of COVID 19 on education. Available at https://voxeu.org/article/impact-covid-19education. Accessed on June 12, 2020.

Collinson, S., Khan, K.,\& Hefferson, J.M. (2015). The effects of media reports on disease spread and important public health measurements. PLoS ONE. 10(11): e0141423. doi:10.1371/journal.pone.0141423.

Dollarhide, M.E. (2019). Social media definition. investopedia. Available at https://www.investopedia.com/terms/s/social-media.asp. Accessed on June 7, 2020.

Depoux, A., Martins, S., Karafillaki, E., Preet, R., Wilder-Smith, A., \& Larson, H. (2020). The pandemic of social media panic travels faster than the COVID-19 Outbreak. Journal of Travel Medicine. Available at https://www.researchgate.net/publication/339677530. Accessed on June 5, 2020.

Foreman, C. (2017). 10 Types of social media and how each can benefit your business. Available on https://blog.hootsuite.com/types-of-social-media/. Accessed on June 14, 2020. 


\section{COVID-19: THE CHANGING LANDSCAPE OF HIGHER EDUCATION IN NIGERIA}

La, V., Pham, T., Ho, M., Nguyen, K.P., Vuong, T., Nguyen, H.T., Tran. T., Khuc, Q., Ho, M.,\& Vuong, Q. (2020). Policy response, social media and science journalism for the sustainability of the public health system amid COVIDOutbreak: The Vietnam Lessons. Sustainability. 12. 1-27. Available on https://www.researchgate.net/publication/339998312. Accessed on June 5, 2020.

Larson, H.J. (2018). The biggest pandemic risk? Viral misinformation. nature .Available at https://www.researchgate.net/publication/328326703. Accessed on June 5, 2020. Catay-Medina

Mejia, C.R., Ticona, D., Rodriguez-Alarcon, J.F., Campos-Urbina, A.M., J.B., PortaQuinto, T., Garayar-Peceros, H., Ignacio-Quinte, C., Esteben, R.F.C., Mamani, P.G.R., \& Tovani-Palone, M.R. (2020). The media and their informative role in the face of the coronavirus disease 2019 (COVID-19): Validation of fear perception and magnitude of the issue (MED-COVID-19). Electronic Journal of General Medicine. 17(6). 1-6.

Oh, S., Lee, S.Y., Han, C. (2020). The effects of social media use on preventive behaviour during infectious disease outbreaks: The mediating role of selfrelevant emotions and public risk perception. Health Communication. 1-11. DOI:10.1080/10410236.2020.1724639.

Olajuwon, O. (2020). Contextualizing COVID 19 Risk communication and community engagement in Sub-Saharan Africa for effective epidemic control: Fighting the 'Infodemic'. https://www.internationalhealthpolicies.org/blogs/contextualizing-covid19-risk-communication-and-community-engagement-in-sub-saharan-africa-foreffective-epidemic-control-fighting-the-infodemic/. Accessed on June 4, 2020.

Onyekwena, C.\&Ekeruche, M.A (2020). Understanding the impact of the COVID 19 Outbreak on the Nigerian Economy. Africa in Focus. Available at https://www.brookings.edu/blog/africa-in-focus/2020/04/08/understanding-theimpact-of-the-covid-19-outbreak-on-the-nigerian-economy/. Accessed on May 30, 2020.

Ozili, P. (2020). COVID 19 in Africa: Socio economic impact, policy response and opportunities. SSRN Electronic Journal. 1-35.

https://www.researchgate.net/publication/340610720. Accessed on June $2^{\text {nd }}$, 2020.UNESCO (2020). Coronavirus Impacts Education.

https://en.unesco.org/themes/education-emergencies/coronavirus-school-closures. Accessed on June 4, 2020. 


\section{COVID-19: THE CHANGING LANDSCAPE OF HIGHER EDUCATION IN NIGERIA}

Possetti, J.\& Bontcheva, K. (2020). Disinfomedic: Deciphering COVID 19

Disinformation. United Nations Educational, Scientific and Cultural Organization (UNESCO). Available at https://en.unesco.org/sites/default/files/disinfodemic_.pdf. Accessed on June 4, 2020.

Sokolov,M. (2020). The Pandemic Infodemic: How Social Media Helps (and Hurts) DuringtheCoronavirusOutbreak.Availableonhttps://www.thedrum.com/opinion/ 2020/03/03/the-pandemic-infodemic-how-social-media-helps-and-hurts-during-thecoronavirus. Accessed on June 4, 2020.

Tsui, E., Rao, R.C., Carey, A.R., Feng, M.T., \& Provencher, L.M. (2020). Using Social Media to Disseminate Ophthalmic Information During the COVID 19 Pandemic. Available at doi: 10.1016/j.ophtha.2020.05.048. Accessed on June 7,2020.

Wielderhold, B.K (2020). Using social media to our advantage: Alleviating anxiety during a pandemic. Cyberpsychology, Behavior and Social Networks. 23(4). 197-199.

Zhao, S.,Wu, C.J., Kuang Y.,\& Ben-Arieh, D.(2015). information dissemination and human behaviours in epidemic. In Cetinkaya, S.\& Ryan, J.K. Proceedings of the 2015 industrial and systems engineering research conference. 1-20. Mediate. 